\title{
25 Research Soure \\ Quality of life and associated factors among women with obstetric fistula in Ethiopia
}

\author{
Biruktawit Matiwos \\ Ras Desta hospital \\ Getachew Tesfaw \\ University of Gondar \\ Asmare Belete \\ Amanuel Mental specialized hospital \\ Dessie Abebaw \\ University of Gondar College of Business and Economics \\ shegaye shumet ( $\square$ shumetshegaye@yahoo.com ) \\ University of Gondar https://orcid.org/0000-0001-7714-7455
}

\section{Primary research}

Keywords: Quality of life, Fistula, Ethiopia

Posted Date: August 5th, 2020

DOI: https://doi.org/10.21203/rs.3.rs-51612/v1

License: @ (1) This work is licensed under a Creative Commons Attribution 4.0 International License. Read Full License

Version of Record: A version of this preprint was published at BMC Women's Health on August 28th, 2021. See the published version at https://doi.org/10.1186/s12905-021-01458-3. 


\section{Abstract}

\section{Background}

The physical, emotional and social suffering associated with continuous leakage of urine has a profound impact on women quality of life. The aim of this study was to assess quality of life and associated factors among obstetric fistula patients in Ethiopia, has a significant role for further intervention.

Objective

To assess quality of life and associated factors among obstetric fistula patients in Ethiopia, 2017.

Methods

In this cross-sectional study, 289 women with obstetric fistula were recruited for interviews, using the systematic random sampling technique. The World Health Organization Quality of Life - Brief (WHOQOL-BREF) Version was used to assess quality of life. The Jacob perceived stigma scale and the Oslo-3 social support instruments were used to assess the factors. We computed simple and multiple linear regression analysis to assess factors associated with quality of life. P-value $<0.05$ was declared statistically significant.

Result

Of 289 women studied, only $12.1 \%$ felt satisfied with their general state of health and quality of life. In the physical health domain, the mean quality of life score was $40.78 \pm .78$. In the psychological domain, the mean quality of life score was $39.96 \pm .82$. In the social and environmental domain, the mean quality of life score was $32.9 \pm .95,36.45 \pm .8$ respectively. Duration of incontinence (unstandard $\beta=-3.8,95 \% \mathrm{Cl}(-6.95,-.62)$, patients coming for surgical procedure $(\beta=-4.4,95 \% \mathrm{Cl}(-7.64,-1.2)$, poor social support $(\beta=-6.14,95 \% \mathrm{Cl}(-8.8,-3.4)$, Co-morbid anxiety $(\beta=-4,95 \% \mathrm{Cl}(-7,-1.1)$ and depression $(\beta=-9.2,95 \% \mathrm{Cl}(-12,-6.4)$ were negatively associated with physical domain of quality of life. Co-morbid anxiety $(\beta=-11,95 \% \mathrm{Cl}(-14.8,-7.3)$, employment $(\beta=9.1,95 \% \mathrm{Cl}(.5,17.6)$, number of children $(\beta=2.1,95 \% \mathrm{Cl}(.8,3.4)$, and depression $(\beta=-6.3,95 \% \mathrm{Cl}(-9.7,-2.9)$ were associated with a psychological domain. Duration of incontinence $(\beta=-8.1,95 \% \mathrm{Cl}(-12.82,-3.4)$, poor social support $(\beta=-7.8(-12,-3.6)$, patients coming for surgical procedure $(\beta=-12,95 \% \mathrm{Cl}(-17.4,-6.4)$ and co-morbid anxiety $(\beta=-9.2,95 \% \mathrm{Cl}(-13.8$, 4.5) were negatively associated with social domain of quality of life. Number of children present $(\beta=2.4,95 \% \mathrm{Cl}(.82,3.6)$, and poor social support $(\beta=-5.5,95 \% \mathrm{CI}(-9.5,-1.5)$ were significantly associated with an environmental domain of quality of life.

Conclusion and recommendation

Co-morbid depression and anxiety, poor social support, duration of urine incontinence, employment, number of children, and duration of hospital stay were factors significantly associated with domains of QOL. Treating co-morbid depression and anxiety, strong social support and controlling urine incontinence is necessary to increase women's domain of quality of life.

\section{Introduction}

Obstetric fistula (OF) is an abnormal connection between the vagina and rectum or between the vagina and bladder due to the product of prolonged, obstructed and unattended labor (1). Globally, greater than two million women are living with OF and in Ethiopia, 10.6 per 1000 women were living with this problem (2).

In developing countries, it is characterized by persistent leakage of urine resulting in perinea wetness, excoriation and pain, and a pervasive urinary odor which affected women's quality of life(3).It covers both medical and nonmedical aspects of life including physical; psychological; social functioning and perception of health status, pain, and overall satisfaction with life(4). World Health Organization describes broad ranging concept QOL as an individual's perception of their position in life in the context of the culture and value systems in which they live and in relation to their goals, expectations, standards, and concerns(5).

Urinary incontinence (UI) is one of the three chronic health conditions that most adversely affect an individual's health-related quality of life (HRQOL)(6). Sever birth injuries like obstetric fistula has a profound effect on women's quality of life(7). Although it is not life-threatening; failure to control sphincters can severely affect a woman's quality of life by limiting her physical, social, psychological and sexual functioning $(8,9)$. In a debilitating condition, in whichever form, sweepingly affects the QOL of the patients through generating feelings of anger and sadness, embarrassment, loss of self-esteem. An impaired sexual relationship, disrupted work environment as well as the dependent lifestyle also affects patients QoL(10-12). 
Many fistula cases occur among women in traditional cultures, where women's status and self-worth may depend almost entirely on marriage and childbearing(13). The bad odor arising from incontinence often results in negative social consequences particularly when it becomes evident that the condition is chronic(14). Sexual activity may be restricted or avoided entirely due to the crippling effect of the diseases(15).Fistula patients do not only suffer from physical discomfort, but they may also have to get the deal with its far-reaching effect on their emotional, psychological well-being and sleep deprivation following this morbidity(16).

Coexistent of severe depression and other mental co-morbidities which commonly occurs in fistula patients significantly affect the degree in which the patient perceives incontinence, which is significant in altering QOL and general functioning of the patients $(11,17)$.

Despite OF is treatable with physiotherapy, medication or surgery, there remain a profound stigma and feeling of humiliation attached to these condition even after surgical repair (11). All this demonstrated that QOL impairment among fistula patients is an obstacle in good physical and social well-being and to the patient's maintenance of general health and treatment(18).

Understanding health related quality of life is considered as an essential outcome for clinical trials and management (19). The goal of treating the whole bladder should be to not only repair the fistula but improve QOL as well(20).

Despite obstetric fistula is treatable, in developing countries including Ethiopia due to low skilled obstetric care access and low infrastructure to reach health facility for labor women are suffering with this problem. And this problem adversely affects women's healthrelated quality of life. Therefore; the aims of this study was to assess quality of life and associated factors among obstetric fistula patients to prevent further complication.

\section{Methods And Materials}

Study setting and population: Institution based cross-sectional study design was used among fistula patients in Addis Ababa Hamlin fistula hospital and outreach centers in Ethiopia between May and July 2017. The study was conducted in Addis Ababa and five regional cities of Ethiopia where centers for Hamlin fistula hospital are found. These fistula hospitals had built in five permanent outreach centers in strategic locations of Ethiopia in addition to the main hospital in Addis Ababa. These five hospitals include Bahirdar and Mekele in northern, Yirgalem in southern, Metu in southwestern and Harar in the eastern part of Ethiopia. Each outreach centers have a ward, an operating room, educational and administrative facilities, as well as other essential facilities. The outreach centers are built adjacent to existing regional hospitals and offer a discrete entrance for fistula patients and women at high risk of obstructed labor who might otherwise be turned away from the main hospital. The main hospital in Addis Ababa is dedicated to treating the complicated cases of fistula injuries and serving other regional Hamlin Fistula Centers. The village Desta Mender in Addis Ababa is involved in teaching and training patients that cannot be fully cured in addition to giving care for them. By considering the average number of patients per month in each center, the proportional allocation was done then systematic random sampling technique was used to select the participants from outpatient and inpatient department.

\section{Measurement}

Quality of life of patients was assessed by 26 item of WHOQOL-BREF questionnaire. The questionnaire consists of 2 parts. The first part evaluates the patient's subjective assessment of quality of life and satisfaction with their state of health, while the second part evaluates the 4 domains: physical health, psychological, social health and the environment. QOL raw scores were transformed into a range between 0 100 and scores closer to hundred had a good quality of life.

Social support- was measured using the Oslo -3 items social support scale and scores ranging between 3 and $14: 3-8=$ poor social support; 9-11 = intermediate social support; and 12-14 = strong social support.

Perceived stigma - based on Jacoby perceived stigma scale: a score of 1 and above indicate the patient is stigmatized.

Discrimination experience score of 1 and above using experienced daily discrimination scale indicate the patient had experienced discrimination.

Anxiety and depression-scores of 0-7 in respective subscales are considered normal, with 8-10 borderline and 11 or over indicates clinical using HADS

\section{Data collection}


Data were collected by face-to-face interviews using a semi-structured questionnaire. The questionnaires including socio-demographic, QOL, social support, anxiety and depression, perceived stigma, and discrimination experience. The questionnaire was designed in English and was translated to Amharic, Aphan Oromo and Tigrigna and back to English for its consistency. Data were collected by trained data collectors using Amharic, Aphan Oromo and Tigrigna version of the questionnaire for a month. Data collectors were trained on how to interview patients and explain unclear questions and the purpose of the study. Furthermore, they were made aware about ethical principles, such as confidentiality/ anonymity/ data management, and securing respondents' informed consent for participation.

\section{Data processing and analysis}

Data were checked for completeness and consistency. A coded variable was entered into EpiData version 3.1, then exported to and analyzed using SPSS version-20. Descriptive statistics (frequency, percent, mean, and standard deviation) were used to summarize the distribution of variables. Simple linear regression analysis was performed to test an association between quality of life and each independent variable. Variables with $\mathrm{p}$-value $\leq 0.05$ during simple linear regression analysis were selected for further analysis in multiple linear regression analysis and model fitness test (adjusted $\mathrm{R}^{2}$ ) was also checked. Factors associated with quality of life were expressed as adjusted unstandardized $\beta$ coefficient by employing $95 \%$ confidence level. A p-value of $<0.05$ was considered as statistically significant.

\section{Ethical consideration}

Ethical clearances were obtained from the ethical review committee of University of Gondar and Amanuel Mental Specialized Hospital. A formal letter obtained from Amanuel mental specialized hospital and submitted to Hamlin fistula ethical review committee for getting ethical clearance to do in each hospital. We received written informed consent from study participants and assent from their guardians after explain the purpose of the study. Confidentiality was maintained by omitting their personal identification.

\section{Results}

A total of 289 participants took part in the study, with a response rate of $90 \%$. The mean age of the participants was $27(\mathrm{SD}, 6.13)$ years. Nearly, half of the patients,i.e. $N=148(51.2 \%)$ were lived with their spouse; $175(61 \%)$ were Orthodox Christian; $157(54 \%)$ were unable to read and write, and 144(50\%) were jobless with its occupational attainment(table1).

\section{Obstetric and fistula related characteristics of the respondents}

The majority of the respondents, 218(75.4\%) had VVF; 71(24.6\%) had RVF/ RVF + VVF types of fistula; 125(43.4\%) incontinent for a year and below a year without any treatment. More than half, i.e. $\mathrm{N}=169(58.5 \%)$ had at least one child, and $\mathrm{N}=160$ (55.4\%) had history of still birth. The mean age of participants at the first marriage and first pregnancy were 15.65 $\pm 3.6,17.49 \pm 3.73$ respectively (table2).

\section{Psychosocial factors}

Regarding psychosocial factors of respondents, 152(52.6\%) had poor social support; 49(30.4\%) had moderate social support; $240(83 \%)$ were stigmatized, and 243(84\%) had experience of discrimination (table3).

\section{Prevalence of depression and anxiety among respondents}

Concerning the co-morbid mental illness, $51.2 \%$ of the women have co-morbid anxiety and $49.1 \%$ have co-morbid depression (fig1).

\section{Quality of life among obstetric fistula patients}

In the current study, from the total participants $12.1 \%$ had felt satisfied for their general health status. The overall mean score of quality of life among fistula patients was 37.52 (95\% Cl 36.26, 38.73) with a standard deviation of 10.99. Mean scores for each domain of WHOQOL were $40.78 \pm 0.78$ for physical domain; $39.96 \pm 0.82$ for psychological; $32.9 \pm 0.95$ for social domain, and $36.45 \pm 0.8$ for environmental domain of quality of life (table4).

\section{Factors associated with quality of life}

Simple linear regression analysis was carried out between WHO-BREF domains and each independent variable. Variables with p-value $\leq 0.05$ during simple linear regression analysis were selected for further analysis in multiple linear regression analysis. Age, educational status, age at first marriage, age at first pregnancy, type of fistula, incontinence, the reason why the women come to the institution, duration of hospital stay, social support, anxiety, depression, perceived stigma, discrimination were associated with physical domain. For 
psychological domain: age, educational status, occupation, age at first marriage, age at first pregnancy, type of fistula, incontinence, number of children, the presence of stillbirth, a reason why the women come to the institution, social support, anxiety, depression, perceived stigma, and discrimination were associated factors.

For social domain: age, occupation, incontinence, number of children, a reason why the women come to the institution, social support, depression, perceived stigma were factors associated with social domain of quality of life.

For environmental domain: marital status, educational status, presence of children, number of children, reason why the women come to the institution, duration of hospital stay, social support, anxiety, depression, perceived stigma, discrimination were factors associated with environmental domain of quality of life.

Results of multiple linear regressions showed that: women incontinent for more than 5 years, women with co-morbid anxiety and depression were significantly associated with physical domain. Four explanatory variables in the psychological domain (women's' who have been employed in private, number of children, co-morbid anxiety and depression were associated factors). Urine incontinence, poor social support, women come to surgery and anxiety were factors associated with social domain and number of children and social support were found to be statistically significant with environmental domain of quality of life (table5).

\section{Discussion}

In Ethiopia, like many other women in remote areas of poor countries, most women who develop untreated fistulas give birth at home without assistance from skilled attendants. These women face different obstetric related complications which result in compromised quality of life. In the this study, women's mean quality of life in physical, psychological, social and environmental domains of QOL were $40.78 \pm .776,32.90 \pm .952,39.96 \pm .817$ and $36.45 \pm .802$ respectively. This low quality of life might be related with women intense fear of developing another fistula, commonly from sex and child birth which leads them to isolation, marital conflict, and/or economic vulnerability. Some women's also continue to experience mental anguish, stigma and physical problems regardless of the success of the procedure(5). This finding is supported by other studies result $(12,21,22)$.

Regarding predictor variables, women who had been incontinent for greater than five years was significantly associated with physical and psychological domain. Women with long duration of incontinence might unable to control leakage, have poor sleep satisfaction and low daily activity; negative feeling about self and life is meaningless and finally result in depression. Study showed $14 \%$ of women attempted suicide because of depressive symptoms (12). The finding is consistent with a result from $(12,21,23)$. Surgery significantly increased the quality of life for women with fistula (12). However, in our study women who came for surgery decrease their physical domain of quality of life by 4 in every unit increase for surgery visit. The emotion related to incontinence might affect their travel with public transport because majority of fistula cases come from distance area. For example; a study in rural west Ethiopia(12) showed that participants reported people used to hold their nose, laugh or talk about the smell when they approached. The other possible reason might be fear to die related to surgical procedure which induced stress. The score of social domain of quality of life decreased by 11 every unit increase for surgery visit. This might be due to fear of lack of social support at hospital stay after surgical procedure.

Poor social support was negatively associated with physical, social and environmental domain of QOL. Women with physical challenges might need assistance from husband, family members, relatives and community members but studies showed (24) women with fistula divorced because of their fistula and lacks support. Obstetric fistula victim women have lack of potential social assistance after operational programs which lead them to anger and sadness $(25,26)$. The emotion related to physical challenges might also affect their relationships at home, with friends and husband. This feelings result in a loss of control over daily routines i.e self care, household chores, and filling the role expected of a wife in the community (25). Many women were assertive and resilient with regard to advocating for their fistula care and relationship needs which brings low linkages to income generation opportunities $(5,20)$. This is supported by studies in Malawi and Tanzania $(27,28)$.

Due to different reasons anxiety and depressive symptoms are common in obstetric fistula women. Between $23.3 \%$ and $38.8 \%$ of fistula women had major depression $(29,30)$. In this study half of the patients have co-morbid anxiety. The presence of anxiety symptom in our study affects patients' physical, psychological and social quality of life. This anxiety and depressive symptoms might be related with loss of child, loss of ability to work and acceptance, lack of social support. For example, in current study the mental health of the women increased by 2 in a number of children alive. The other reason might be related to stigmatizing nature of obstetric fistula, they had a feeling of being inferior, sinful and losing hopes in the future. They prefer to withdraw from social activity and spent their time alone (25). This finding is consistent with other study findings $(30,31)$. 
Mostly in the remote area of the country(Ethiopia) women's were powerless in their married lives and women while living with a fistula stopped working and remained at home (25). A study showed $50 \%$ of women with fistula economically impoverished by job loss (24). In this study the score of psychological domain of quality of life increased by 9 in every unit increase in employment.

\section{Limitation Of The Study}

This study has several limitations. Social desirability and recall bias might be present. Because data collection method was face-to-face interview which might lead individuals to respond socially acceptable answer during the interview process.

The design of the study was cross-sectional; therefore, we were unable to conclude the observed/reported associations may not necessarily any causal direction.

Furthermore, we did not assess patients' change of quality of life before repair and after repair of obstetric fistula.

\section{Conclusion}

In this study quality of life among obstetric fistula patients was low. Depression, anxiety, poor social support, incontinence, employment, number of children present were factors associated with quality of life. Therefore; we recommend clinicians to consider co-morbid depression and anxiety, social support and income generation opportunities to increase quality of life.

\section{Declarations}

\section{Acknowledgment}

The authors acknowledge the University of Gondar and Amanuel Mental Specialized Hospital for funding the study. We extend our gratitude to data collectors, supervisors and study participants for their time and effort.

Authors' contribution: BM developed the proposal, supervised the data collection, analyzed the data and wrote the draft manuscript. GT, AB revised the proposal, checked the data analysis.SS, checked data analysis, writing, revised and approved the manuscript.

Funding: University of Gondar and Amanuel mental specialized hospital funded for the study

Competing interests. The authors declare that they have no competing interests

Patient consent: Informed consent was obtained from participants

Ethical approval and consent to participate: Ethical approval was obtained from joint ethical review committees of the University of Gondar and Amanuel mental specialized hospital.

Provenance and peer review: Not commissioned; externally peer reviewed.

Availability of data and materials: All the data are included in the manuscript

Consent to publication: Not applicable

\section{References}

1. Wall LLJTL. Obstetric vesicovaginal fistula as an international public-health problem. 2006;368(9542):1201-9.

2. Vangeenderhuysen C, Prual A, el Joud, DOJIJoG. Obstetrics. Obstetric fistulae: incidence estimates for sub-Saharan Africa. 2001;73(1):65-6.

3. Berlim MT, Fleck MJBJoP. "Quality of life": a brand new concept for research and practice in psychiatry. 2003;25(4):249-52.

4. Bramston P, Chipuer H, Pretty GJJoIDR. Conceptual principles of quality of life: an empirical exploration. 2005;49(10):728-33.

5. Donnelly K, Oliveras E, Tilahun Y, Belachew M, Asnake MJC. health, sexuality. Quality of life of Ethiopian women after fistula repair: implications on rehabilitation and social reintegration policy and programming. 2015;17(2):150-64.

6. science WGJS, medicine. The World Health Organization quality of life assessment (WHOQOL): position paper from the. World Health Organization. 1995;41(10):1403-9.

7. Schultz SE, Kopec JAJHR. Impact of chronic conditions. 2003;14(4):41-53. 
8. Herzog AR, Diokno AC, Brown MB, Fultz NH, Goldstein NEJJotAGS. Urinary incontinence as a risk factor for mortality. 1994;42(3):2648.

9. Walker GJ, Gunasekera PJluj. Pelvic organ prolapse and incontinence in developing countries: review of prevalence and risk factors. 2011;22(2):127-35.

10. Arrowsmith S, Hamlin EC, Wall LLJO, survey g. Obstructed labor injury complex: obstetric fistula formation and the multifaceted morbidity of maternal birth trauma in the developing world. 1996;51(9):568 - 74.

11. Melville JL, Walker E, Katon W, Lentz G, Miller J, Fenner DJAjoo, et al. Prevalence of comorbid psychiatric illness and its impact on symptom perception, quality of life, and functional status in women with urinary incontinence. 2002;187(1):80-7.

12. Nielsen H, Lindberg L, Nygaard U, Aytenfisu H, Johnston $O$, Sørensen B, et al. A community-based long-term follow up of women undergoing obstetric fistula repair in rural Ethiopia. 2009;116(9):1258-64.

13. Mselle LT, Moland KM, Evjen-Olsen B, Mvungi A, Kohi TWJBwsh. " I am nothing": experiences of loss among women suffering from severe birth injuries in Tanzania. 2011;11(1):49.

14. Muleta M, Fantahun M, Tafesse B, Hamlin EC, Kennedy RJEAMJ. Obstetric fistula in rural Ethiopia. 2007;84(11):525.

15. Vigod SN, Stewart DEJP. Major depression in female urinary incontinence. 2006;47(2):147-51.

16. Kabir M, Iliyasu Z, Abubakar I, Umar UJAoAM. Medico-social problems of patients with vesico-vaginal fistula in Murtala Mohammed Specialist Hospital. Kano. 2003;2(2):54-7.

17. Zeleke BM, Ayele TA, Woldetsadik MA, Bisetegn TA, Adane AAJBp. Depression among women with obstetric fistula, and pelvic organ prolapse in northwest Ethiopia. 2013;13(1):236.

18. Rowles SV, Prieto L, Badia X, Shalet SM, Webb SM, Trainer PJJTJoCE, et al. Quality of life (QOL) in patients with acromegaly is severely impaired: use of a novel measure of QOL: acromegaly quality of life questionnaire. 2005;90(6):3337-41.

19. Feeny D, Furlong W, Saigal S. Sun JJSs, medicine. Comparing directly measured standard gamble scores to HUI2 and HUI3 utility scores: group-and individual-level comparisons. 2004;58(4):799-809.

20. De Bernis, LJIJoG. Obstetrics. Obstetric fistula: guiding principles for clinical management and programme development, a new WHO guideline. 2007;99:S117-S21.

21. Singh V, Jhanwar A, Mehrotra S, Paul S, Sinha RJAJoU. A comparison of quality of life before and after successful repair of genitourinary fistula: Is there improvement across all the domains of WHOQOL-BREF questionnaire? 2015;21(4):230-4.

22. Umoiyoho A, Inyang-Etoh E, Abah G, Abasiattai A, Akaiso OJR, Health R. Quality of life following successful repair of vesicovaginal fistula in Nigeria. 2011;11(3).

23. Browning A, Menber, BJBAIJoO. Gynaecology. Women with obstetric fistula in Ethiopia: a 6-month follow up after surgical treatment. 2008;115(12):1564-9.

24. Gharoro E, Agholor KJJoO. Gynaecology. Aspects of psychosocial problems of patients with vesico-vaginal fistula. 2009;29(7):644-7.

25. Gebresilase YTJljowsh. A qualitative study of the experience of obstetric fistula survivors in Addis Ababa. Ethiopia. 2014;6:1033.

26. Imoto A, Matsuyama A, Ambauen-Berger B, Honda SJIJoG. Obstetrics. Health-related quality of life among women in rural Bangladesh after surgical repair of obstetric fistula. 2015;130(1):79-83.

27. Mselle LT, Evjen-Olsen B, Moland KM, Mvungi A, Kohi TWJJoO, Canada G. " hoping for a normal life again": reintegration after fistula repair in rural Tanzania. 2012;34(10):927-38.

28. Johnson, KJIJoG. Obstetrics. Incontinence in Malawi: analysis of a proxy measure of vaginal fistula in a national survey. 2007;99:S122s9.

29. Goh JT, Sloane KM, Krause HG, Browning A. Akhter SJBAIJoO, Gynaecology. Mental health screening in women with genital tract fistulae. 2005;112(9):1328-30.

30. Weston K, Mutiso S, Mwangi JW, Qureshi Z, Beard J, Venkat PJIJoG, et al. Depression among women with obstetric fistula in Kenya. 2011;115(1):31-3.

31. Senra C, Pereira MGJRdAMB. Quality of life in women with urinary incontinence. 2015;61(2):178-83.

\section{Tables}

Table 1: socio-demographic characteristics of women with obstetric fistula in Ethiopia, 2017(n=289) 


\begin{tabular}{|c|c|c|c|}
\hline variables & Categories & frequency & Percent (\%) \\
\hline Age & & $27 \pm 6.13$ & \\
\hline \multirow[t]{3}{*}{ Religions } & Orthodox & & 61 \\
\hline & Muslim & & 19.8 \\
\hline & Protestant & & 19.2 \\
\hline \multirow[t]{2}{*}{ Marital status } & With spouse & 148 & 51.2 \\
\hline & Without spouse & 141 & 48.8 \\
\hline \multirow[t]{3}{*}{ Education } & Unable to read and write & 157 & 54 \\
\hline & Primary school & 121 & 42 \\
\hline & Secondary school and above & 11 & 4 \\
\hline \multirow[t]{3}{*}{ Occupation } & Private business & 132 & 45.5 \\
\hline & Jobless & 144 & 50 \\
\hline & Others* & 13 & 4.5 \\
\hline
\end{tabular}

Others $^{*}=$ students + employed

Table 2: Distribution of obstetric and fistula related factors among women with obstetric fistula in Ethiopia,2017 (n=289) 


\begin{tabular}{|c|c|c|c|}
\hline Variables & Categories & Freq/mean $\pm S D$ & Percent (\%) \\
\hline Mean age at the first marriage & & $15.65(S D \pm 3.6)$ & \\
\hline Mean age at first pregnancy & & $17.49 \pm 3.73$ & \\
\hline \multirow[t]{2}{*}{ Type of fistula } & VVF & 218 & 75.4 \\
\hline & $\mathrm{RVF} / \mathrm{RVF}+\mathrm{VVF}$ & 71 & 24.6 \\
\hline \multirow[t]{3}{*}{ Duration of incontinence before surgical repair } & $<1$ & 125 & 43.4 \\
\hline & $1-5$ & 103 & 35.4 \\
\hline & $>5$ & 61 & 21.2 \\
\hline \multirow[t]{2}{*}{ Women who have children } & Yes & 169 & 58.5 \\
\hline & No & 120 & 41.5 \\
\hline Number of children present & Mean (SD) & $2 \pm 1.32$ & \\
\hline \multirow[t]{2}{*}{ stillbirth } & Yes & 160 & 55.4 \\
\hline & No & 129 & 44.6 \\
\hline Mean number of previous stillbirths & & $2 \pm 1.22$ & \\
\hline \multirow[t]{4}{*}{ Reason for coming to the institution } & New visit to seek help & 45 & 15.6 \\
\hline & Waiting for surgical procedure & 190 & 65.7 \\
\hline & For follow up & 17 & 5.9 \\
\hline & For counseling & 4 & 1.4 \\
\hline \multirow[t]{3}{*}{ Intervention } & Surgery & 223 & 77.2 \\
\hline & Counseling & 10 & 3.5 \\
\hline & physiotherapy & 4 & 1.4 \\
\hline \multirow[t]{3}{*}{ Duration for follow ups } & $<4$ years & 197 & 68.2 \\
\hline & $4-8$ years & 47 & 16.2 \\
\hline & $>8$ years & 45 & 15.6 \\
\hline \multirow[t]{3}{*}{ Hospital stay for intervention } & $<$ six month & 155 & 53.6 \\
\hline & 1-6 month & 109 & 37.7 \\
\hline & >six months & 25 & 8.7 \\
\hline
\end{tabular}

Table 3: Psychosocial factors among women with obstetric fistula in Ethiopia, 2017 ( $n=289)$

\begin{tabular}{|llll|}
\hline Variables & Categories & frequency & Percent (\%) \\
\hline Social support & Poor & 152 & 52.6 \\
\cline { 2 - 4 } & Moderate & 88 & 30.4 \\
\cline { 2 - 4 } & Strong & 49 & 17 \\
\hline \multirow{2}{*}{ Perceived stigma } & Stigmatized & 240 & 83 \\
\cline { 2 - 4 } & Non stigmatized & 49 & 17 \\
\hline Discrimination experience & Discriminated & 243 & 84 \\
\cline { 2 - 4 } & Non discriminated & 46 & 16 \\
\cline { 2 - 4 } & &
\end{tabular}


Table 4: Quality of life among women with obstetric fistula in Ethiopia, $2017(n=289)$

\begin{tabular}{|llll|}
\hline Domain & Mean score of QOL(SD) & Percentage of participants who score below the mean (\%) & 95\%Cl \\
\hline Physical & $40.78 \pm .78$ & $52.2 \%$ & $(39.12,42.31)$ \\
\hline Psychological & $39.96 \pm .82$ & $27.3 \%$ & $(38.21,41.43)$ \\
\hline Social & $32.9 \pm .95$ & $34.9 \%$ & $(30.82,34.89)$ \\
\hline Environmental & $36.45 \pm .8$ & $53.6 \%$ & $(34.84,38.09)$ \\
\hline Overall QOL & $37.52 \pm 10.99$ & & $(36.26,38.73)$ \\
\hline
\end{tabular}

Table 5: Factors associated with quality of life domains among women with obstetric fistula at Addis Ababa fistula hospital and outreach centers, Ethiopia, 2017. ( $n=289)$

\begin{tabular}{|c|c|c|c|c|c|c|c|c|}
\hline \multirow[t]{3}{*}{ variables } & \multicolumn{8}{|c|}{ Quality of life domain } \\
\hline & \multicolumn{2}{|l|}{ physical } & \multicolumn{2}{|l|}{ psychological } & \multicolumn{2}{|l|}{ social } & \multicolumn{2}{|l|}{ environmental } \\
\hline & Unst. $\beta(95 \% \mathrm{Cl})$ & $\mathrm{R}^{2}$ & Unst. $\beta(95 \% \mathrm{Cl})$ & $\mathrm{R}^{2}$ & Unst. $\beta(95 \% \mathrm{Cl})$ & $\mathrm{R}^{2}$ & Unst. $\beta(95 \% \mathrm{Cl})$ & $\mathrm{R}^{2}$ \\
\hline Incontinence & $\frac{-3.8(-6.95,-.62)}{* *}$ & $\mathrm{R} 2=.044$ & - & - & $\underset{* \star \star}{-8.1(-12.82,-3.4)}$ & $\mathrm{R} 2 .=.041$ & - & \\
\hline Reason(surgery) & $\begin{array}{l}-4.4(-7.64,-1.2) \\
\star \star\end{array}$ & $\mathrm{R} 2=.052$ & - & - & $\begin{array}{l}-12(-17.4,-6.4) \\
\star \star \star\end{array}$ & $\mathrm{R} 2=.107$ & $\longrightarrow$ & \\
\hline social support & $\frac{-6.14(-8.8,-3.4)}{\star \star \star}$ & $\mathrm{R} 2=.234$ & - & - & $-7.8(-12,-3.6)$ & $\mathrm{R} 2=.226$ & $-5.5(-9.5,-1.5)$ & $\mathrm{R} 2=.196$ \\
\hline Anxiety & $-4(-7,-1.1) * \star$ & $\mathrm{R} 2=.255$ & $\begin{array}{l}-11(-14.8,-7.3) \\
\star \star \star\end{array}$ & $\mathrm{R} 2=.380$ & $\frac{-9.2(-13.8,4.5)}{\star \star \star}$ & $\mathrm{R} 2=.187$ & 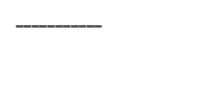 & - \\
\hline Depression & $-9.2(-12,-6.4)$ & $\mathrm{R} 2=.328$ & $\frac{-6.3(-9.7,-2.9)}{\star \star \star}$ & $\mathrm{R} 2=.251$ & $\longrightarrow$ & - & $\longrightarrow$ & - \\
\hline $\begin{array}{l}\text { private } \\
\text { employed }\end{array}$ & $\ldots$ & - & $\underset{\star \star}{9.1}(.5,17.6)$ & $\mathrm{R} 2=.022$ & $\ldots$ & - & - & - \\
\hline $\begin{array}{l}\text { Number of } \\
\text { children present }\end{array}$ & - & - & $2.1(.8,3.4) * *$ & $R 2=.138$ & $\ldots$ & - & $\underset{* \star *}{2.4(.82,3.6)}$ & $\mathrm{R} 2=.074$ \\
\hline
\end{tabular}

** stands for $p<.005, * * *$ stands for $p<.001,(---)$ factors has no association

Figures 


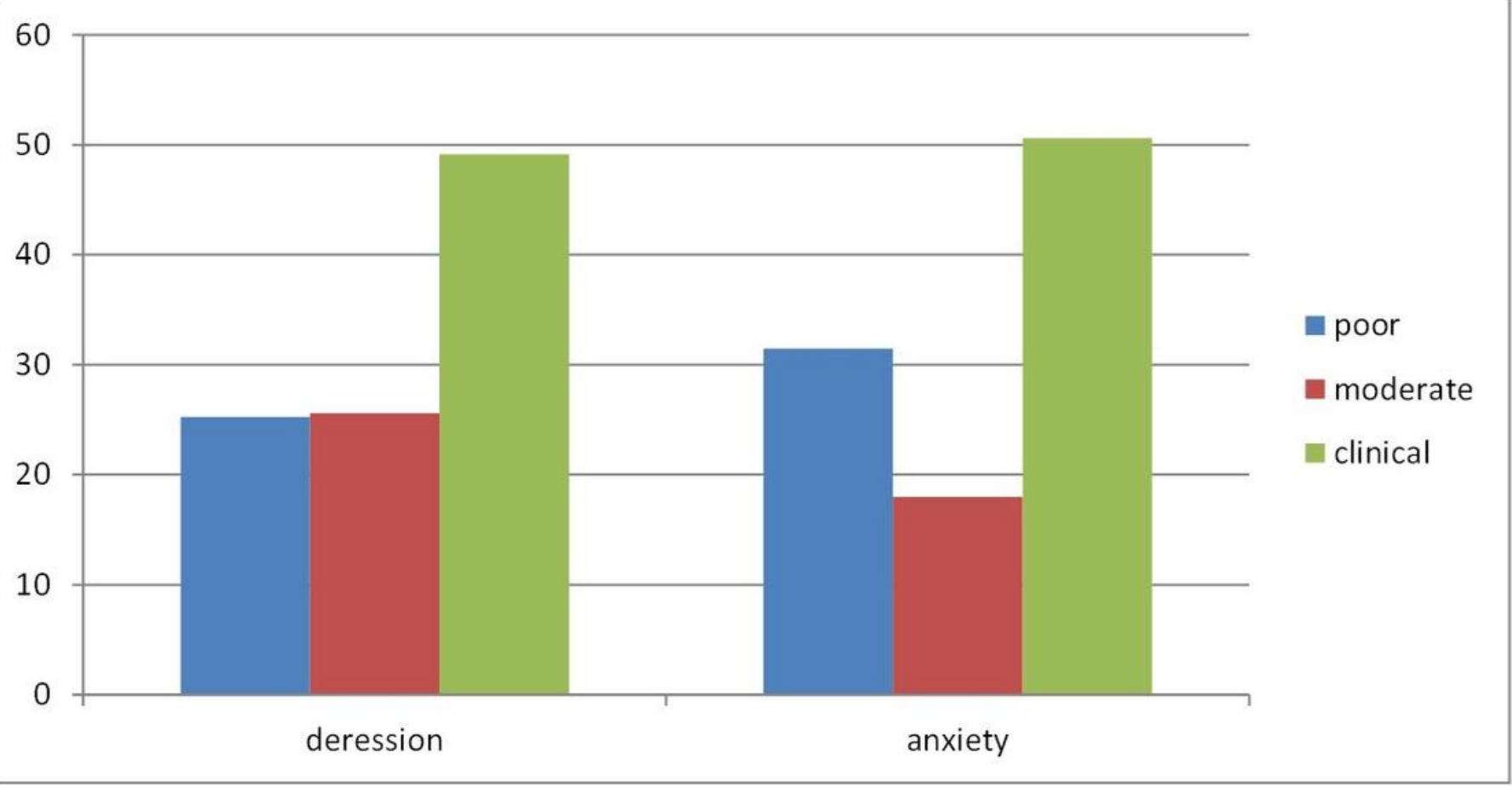

Figure 1

Prevalence of anxiety and depression among women with obstetric fistula in Ethiopia, 2017 ( $n=289)$ 